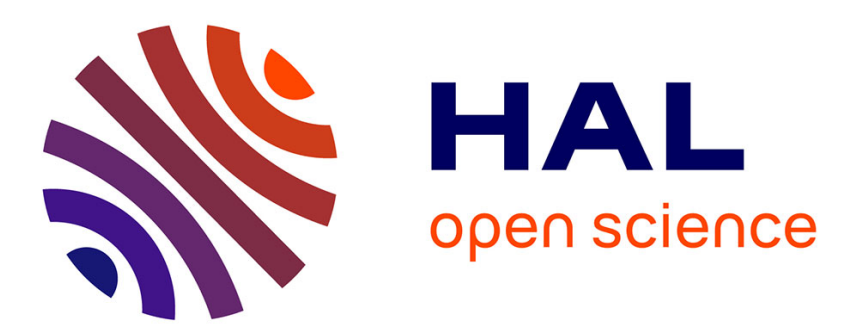

\title{
On the influence of recombination centers on the electrical performance of silicon power rectifiers
}

M. Derdouri, A. Muñoz-Yagüe

\section{To cite this version:}

M. Derdouri, A. Muñoz-Yagüe. On the influence of recombination centers on the electrical performance of silicon power rectifiers. Revue de Physique Appliquée, 1978, 13 (12), pp.729-732. 10.1051/rphysap:019780013012072900 . jpa-00244535

\section{HAL Id: jpa-00244535 https://hal.science/jpa-00244535}

Submitted on 1 Jan 1978

HAL is a multi-disciplinary open access archive for the deposit and dissemination of scientific research documents, whether they are published or not. The documents may come from teaching and research institutions in France or abroad, or from public or private research centers.
L'archive ouverte pluridisciplinaire HAL, est destinée au dépôt et à la diffusion de documents scientifiques de niveau recherche, publiés ou non, émanant des établissements d'enseignement et de recherche français ou étrangers, des laboratoires publics ou privés. 


\title{
ON THE INFLUENCE OF RECOMBINATION CENTERS ON THE ELECTRICAL PERFORMANCE OF SILICON POWER RECTIFIERS
}

\author{
M. DERDOURI and A. MUÑOZ-YAGÜE
}

Laboratoire d'Automatique et d'Analyse des Systèmes du C.N.R.S., 7, avenue du Colonel-Roche, 31400 Toulouse, France

\begin{abstract}
Résumé. - On étudie l'or, le platine et les défauts créés par irradiation électronique en tant que centres recombinants dans les dispositifs au silicium. Les résultats présentés montrent les variations de la durée de vie des porteurs avec les concentrations de centres profonds et d'impuretés dopantes, pour différentes conditions de polarisation. L'influence de la durée de vie des porteurs sur les caractéristiques électriques des diodes PIN de puissance est enfin considérée dans le but de comparer les différentes techniques de contrôle de ce paramètre.
\end{abstract}

\begin{abstract}
The use of gold, platinum and electron irradiation induced defects as recombination centers in silicon devices is studied. Results are presented concerning the variations of carrier lifetime with the concentration of both deep and shallow level impurities, for different bias conditions. The influence of carrier lifetime on the electrical performance of power PIN rectifiers is considered in order to compare the relative advantages of the lifetime controlling techniques.
\end{abstract}

Introduction. - The control of carrier lifetime is a relevant aspect of the design and manufacturing of power rectifiers, as that parameter has a large influence on the most useful electrical characteristics of these devices. The effect of the different recombination centers used for that purpose has been discussed on the basis of the Hall-Shockley-Read theory for a single level recombination center. This approach can be misleading when the considered center introduces several energy levels in the forbidden gap of the semiconductor material, and this is the case for the two impurities (gold and platinum) which are more often considered.

In this paper, we present a more rigorous approach of the case of amphoteric centers, by taking into account the physical interaction between the two levels introduced. The role of gold and platinum in silicon is then studied; the case of silicon in which carrier lifetime is controlled by electron irradiation and annealing is also studied on the basis of the HSR theory for two non interacting levels. Finally, the influence of carrier lifetime on the electrical performance of power rectifiers is briefly considered in order to compare the advantages brought about by the different techniques used for carrier lifetime control.

1. Kinetics of charge carriers. - 1.1 SINGLE LEVEL RECOMBINATION CENTER. - Let us first consider the well known case of a single recombination level, characterised by its concentration $N_{\mathrm{T}}$, its energy level $E_{\mathrm{T}}$, and its capture and emission coefficients $c_{n}, c_{p}, e_{n}, e_{p}$, where $n$ and $p$ are relative to electrons and holes respectively. We have

$$
\begin{aligned}
& e_{n}=c_{n} n_{1}=c_{n} n_{\mathrm{i}} \exp \left(E_{\mathrm{T}}-E_{\mathrm{i}}\right) / k T \\
& e_{p}=c_{p} p_{1}=c_{p} n_{\mathrm{i}} \exp \left(E_{\mathrm{i}}-E_{\mathrm{T}}\right) / k T
\end{aligned}
$$

where $n_{\mathrm{i}}$ is the intrinsic carrier concentration, $E_{\mathrm{i}}$ the intrinsic Fermi level, $T$ the temperature and $k$ the Boltzmann constant. The electron-hole recombination rate is

$$
U=\frac{N_{\mathrm{T}}\left(p n-n_{\mathrm{i}}^{2}\right)}{c_{p}^{-1}\left(n+n_{1}\right)+c_{n}^{-1}\left(p+p_{1}\right)}
$$

where $p=p_{0}+\delta p$ and $n=n_{0}+\delta n$. Subscript 0 stands for equilibrium conditions. The carrier lifetime is defined as

$$
\tau \equiv \frac{n-n_{0}}{U}=\frac{\delta n}{U}
$$

Expression (3) allows [1] to show that if

$$
c_{n} n_{1}+c_{p} p_{1}<c_{p} n_{0}+c_{n} p_{0}
$$

lifetime increases with increasing injection level.

In the case of several independant recombination levels, each level $i$ contributes with an elementary recombination rate $U_{i}$ and the effective lifetime is

$$
\tau^{-1}=\sum_{i} \tau_{i}^{-1}=\left(\frac{\delta n}{\sum_{i} U_{i}}\right)^{-1}
$$

1.2 Amphoteric CENTERs. - Consider now the case of a deep impurity with two energy levels $E_{\mathrm{T}}^{-}$ and $E_{\mathrm{T}}^{+}$where - and + denotes acceptor and donor respectively. Let $N_{\mathrm{T}}^{-}$and $N_{\mathrm{T}}^{+}$be the deep impurity concentration of each occupied level, and $N_{\mathrm{T}}^{0}$ the impurity concentration on the neutral state. The acceptor and donor levels interact : they share the same neutral state centers which participate in the eight elementary processes shown in figure 1 . 


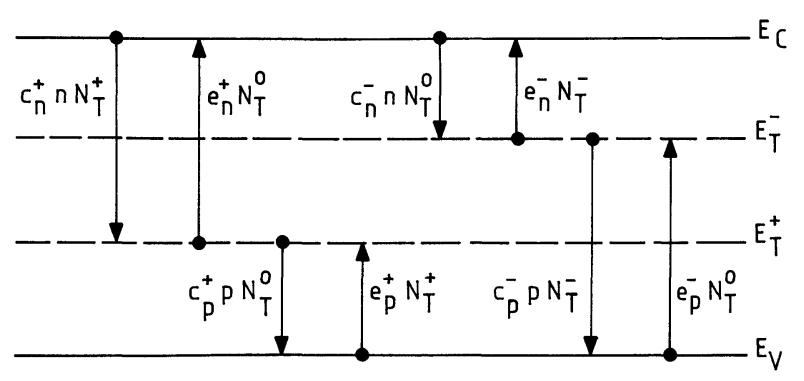

FIG. 1. - Recombination processes for an amphoteric center.

For given values of $N_{\mathrm{T}}$, shallow impurity concentrations $\left(N_{\mathrm{D}}, N_{\mathrm{A}}\right)$ and injection level ( $n$, for example), the following system of equations must be solved :

$$
\begin{aligned}
N_{\mathrm{T}}= & N_{\mathrm{T}}^{-}+N_{\mathrm{T}}^{+}+N_{\mathrm{T}}^{0} \\
U= & U_{n}=c_{n}^{-}\left(n N_{\mathrm{T}}^{0}-n_{1}^{-} N_{\mathrm{T}}^{-}\right)+ \\
& \quad+c_{n}^{+}\left(n N_{\mathrm{T}}^{+}-n_{1}^{+} N_{\mathrm{T}}^{0}\right) \\
N_{\mathrm{T}}^{-}= & N_{\mathrm{T}}\left(c_{n}^{-} n+c_{p}^{-} p_{1}^{-}\right)\left(c_{n}^{+} n+c_{p}^{+} p_{1}^{+}\right) / B \\
N_{\mathrm{T}}^{+}= & N_{\mathrm{T}}\left(c_{p}^{+} p+c_{n}^{+} n_{1}^{+}\right)\left(c_{p}^{-} p+c_{n}^{-} n_{1}^{-}\right) / B \\
B= & \left(c_{n}^{-} n+c_{p}^{-} p_{1}\right)\left(c_{n}^{+} n+c_{p}^{+} p_{1}^{+}\right)+ \\
& \quad\left(c_{n}^{+} n+c_{p}^{+} p_{1}^{+}\right)\left(c_{p}^{-} p+c_{n}^{-} n_{1}^{-}\right) \\
& +\left(c_{p}^{+} p+c_{n}^{+} n_{1}^{+}\right)\left(c_{p}^{-} p+c_{n}^{-} n_{1}^{-}\right)
\end{aligned}
$$

$$
p+N_{\mathrm{D}}-n-N_{\mathrm{A}}+N_{\mathrm{T}}^{+}-N_{\mathrm{T}}^{-}=0 .
$$

The values of $p, N_{\mathrm{T}}^{-}, N_{\mathrm{T}}^{+}, N_{\mathrm{T}}^{0}$ and $U$ are then obtained. The equilibrium values for all the quantities involved $\left(p_{0}, n_{0}, N_{\mathrm{T} 0}, \ldots\right)$ can be obtained by solving the same system of equations, plus the mass action law i.e. $p_{0} \cdot n_{0}=n_{\mathrm{i}}^{2}$. Once $p_{0}$ and $n_{0}$ are known, the lifetime value (4) can be calculated.

2. Carrier lifetime behaviour. - Gold and platinum have been dealt with on the basis of the above formulation for amphoteric deep centers and using the published data for the physical parameters of the energy levels involved. The case of electron irradiated silicon has been treated using the theory for two noninteracting recombination levels. Table I shows the numerical data used in our calculations. Some of the results obtained are presented.
2. 1 HIGH INJECTION LEVEL $\left(p \simeq n \gg N_{\mathrm{D}}, N_{\mathrm{A}}\right)$. The corresponding value of lifetime $\tau_{\mathrm{HL}}$ depends only on the concentration of the deep center and on its kinetic coefficients. The level involved is the nearest to any of the intrinsic bands, whatever is the semiconductor type.

Figure 2 shows the variation of $\tau_{\mathrm{HL}}$ as a function of the concentration $N_{\mathrm{T}}$ for the three cases considered.

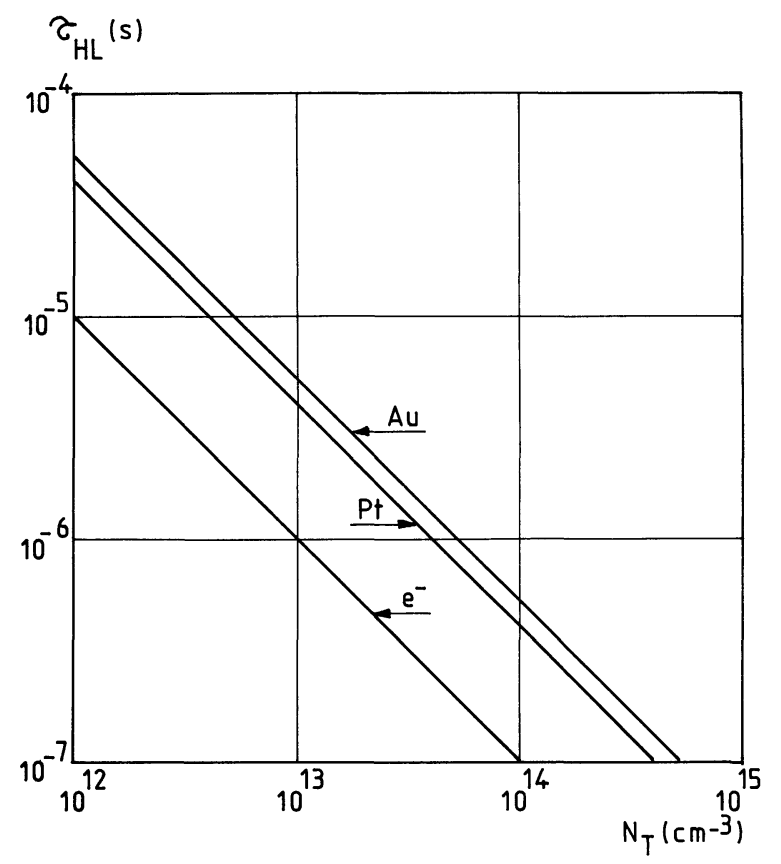

FIG. 2. - Variations of the high level carrier lifetime with the concentration of recombination centers. The curves correspond to gold, platinum and electron irradiation induced defects in silicon.

2. 2 LOW INJECTION LEVEL $\left(\delta n, \delta p \ll N_{\mathrm{D}}, N_{\mathrm{A}}\right)$. The recombination level involved in this case may well not be the same that dominates at high injection level : figures 3 and 4 show the results for N-type

\begin{tabular}{|c|c|c|c|c|}
\hline \multicolumn{2}{|c|}{ Recombination center } & $\begin{array}{c}\text { Energy level } \\
(\mathrm{eV})\end{array}$ & $\begin{array}{l}\text { Capture coefficient } \\
\text { for electrons } \\
\left(\mathrm{cm}^{-3} \mathrm{~s}^{-1}\right)\end{array}$ & $\begin{array}{c}\text { Capture coefficient } \\
\text { for holes } \\
\left(\mathrm{cm}^{-3} \mathrm{~s}^{-1}\right)\end{array}$ \\
\hline \multicolumn{2}{|c|}{ - } & - & - & - \\
\hline \multirow{2}{*}{$\mathrm{Au}[2]$} & Acceptor & $E_{\mathrm{c}}-0.54$ & $1.65 \times 10^{-9}$ & $1.15 \times 10^{-7}$ \\
\hline & Donnor & $E_{\mathrm{v}}+0.35$ & $6.3 \times 10^{-8}$ & $2.4 \times 10^{-8}$ \\
\hline \multirow{2}{*}{$\operatorname{Pt}[3]$} & Acceptor & $E_{\mathrm{c}}-0.24$ & $6.3 \times 10^{-8}$ & $5.15 \times 10^{-8}$ \\
\hline & Donnor & $E_{\mathrm{v}}+0.34$ & $1.56 \times 10^{-8}$ & $1.62 \times 10^{-8}$ \\
\hline \multirow{2}{*}{$e^{-}[4]$} & Vacancy-0 & $E_{\mathrm{c}}-0.17$ & $1.1 \times 10^{-8}$ & $4 \times 10^{-7}$ \\
\hline & Divacancy & $E_{\mathrm{v}}+0.27$ & $9 \times 10^{-8}$ & $8 \times 10^{-6}$ \\
\hline
\end{tabular}
Au-doped and for P-type Pt-doped silicon respectively.

Moreover, the value $\tau_{\mathrm{LL}}$ of the lifetime at low and moderate injection levels depends, not only upon $N_{\mathrm{T}}$ but also on the relative position of the Fermi level and the deep level involved, i.e., on $N_{\mathrm{D}}, N_{\mathrm{A}}$. In general

\section{TABLE I}

Numerical values used in calculations 


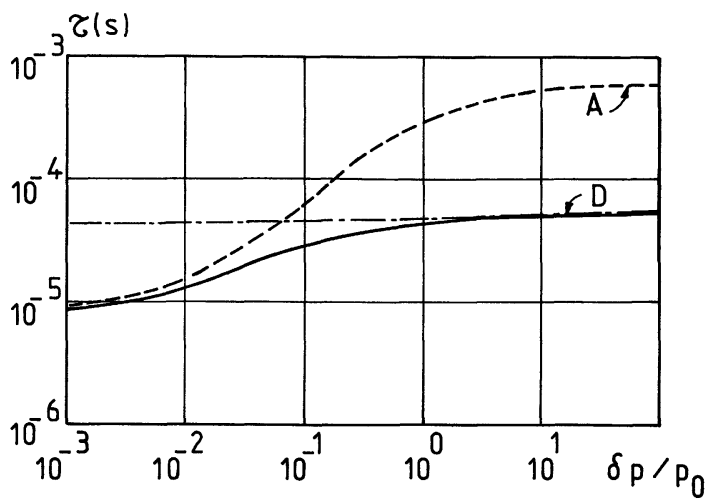

FIG. 3. - Variation of lifetime with injection conditions. Audoped N-type Si. Curve A(D) shows the lifetime when only the acceptor (donor) level is considered. Solid line : lifetime obtained when the two levels (A and D) are taken into account.

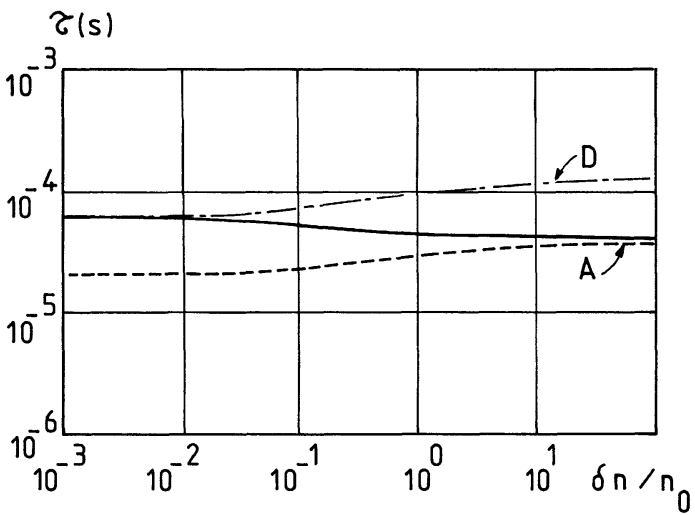

FIG. 4. - Variation of lifetime with injection conditions. Ptdoped P-type Si. Curves are labelled as in figure 3.

only when $N_{\mathrm{T}} \ll N_{\mathrm{A}}, N_{\mathrm{D}}$ the value of $\tau_{\mathrm{LL}}$ can be given independently of $N_{\mathrm{D}}, N_{\mathrm{A}}$. For example, in N-type material, as $N_{\mathrm{D}}$ decreases, the Fermi level approaches the level that dominates the recombination process, $\tau_{\mathrm{LL}}$ increases and becomes greater than $\tau_{\mathrm{HL}}$. This can be accounted for on the basis of relation (5)

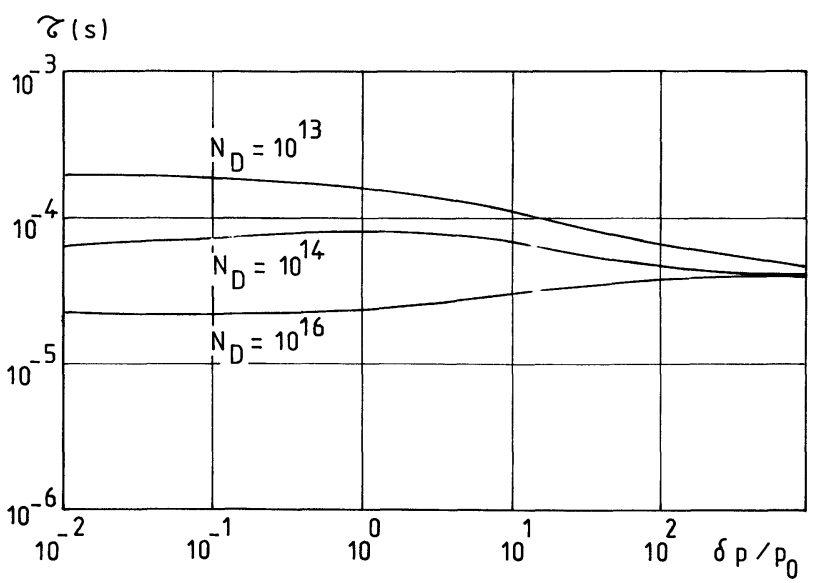

FIG. 5. - Influence of the shallow impurity concentration on the carrier lifetime. Platinum doped N-type Si. by noticing that, for example, in $\mathrm{N}$-type Pt-doped $\mathrm{Si}$ $\left(n_{0}>p_{0}, c_{n}^{-} \simeq c_{p}^{-}\right)$, the condition (5) becomes $n_{1}>n_{0}$ and this implies $E_{\mathrm{c}}-E_{\mathrm{T}}^{-}<E_{\mathrm{c}}-E_{\mathrm{F}}, E_{\mathrm{c}}$ being the conduction band energy level. This effect is most significant for Pt-doped and electron irradiated Silicon, as shown by figures 5 and 6 respectively.

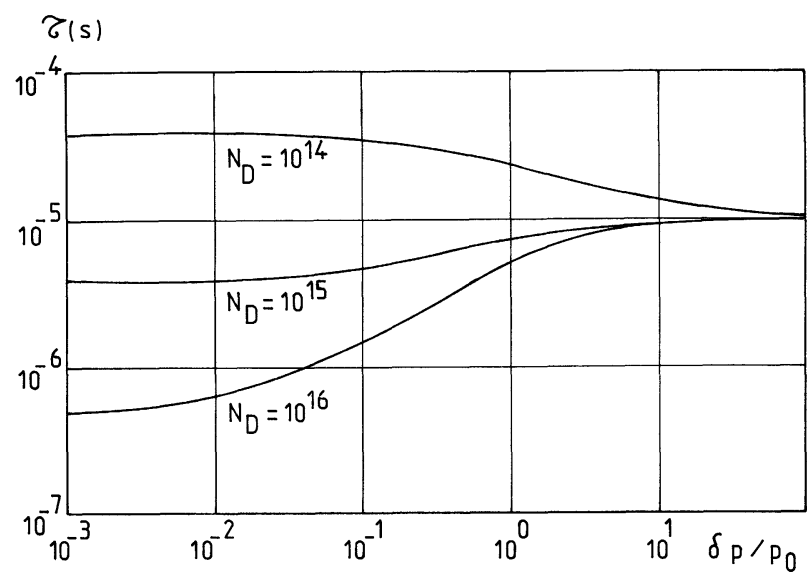

Fig. 6. - Influence of the shallow impurity concentration on the carrier lifetime. Electron irradiated N-type Si.

2.3 Finally, THE CARRIER GENERATION LIFETIME $\tau_{\text {sc }}$ must be considered. Its value is obtained by solving equations (7)-(10), for the conditions of depletion $p=n=0$ which apply within the device space charge

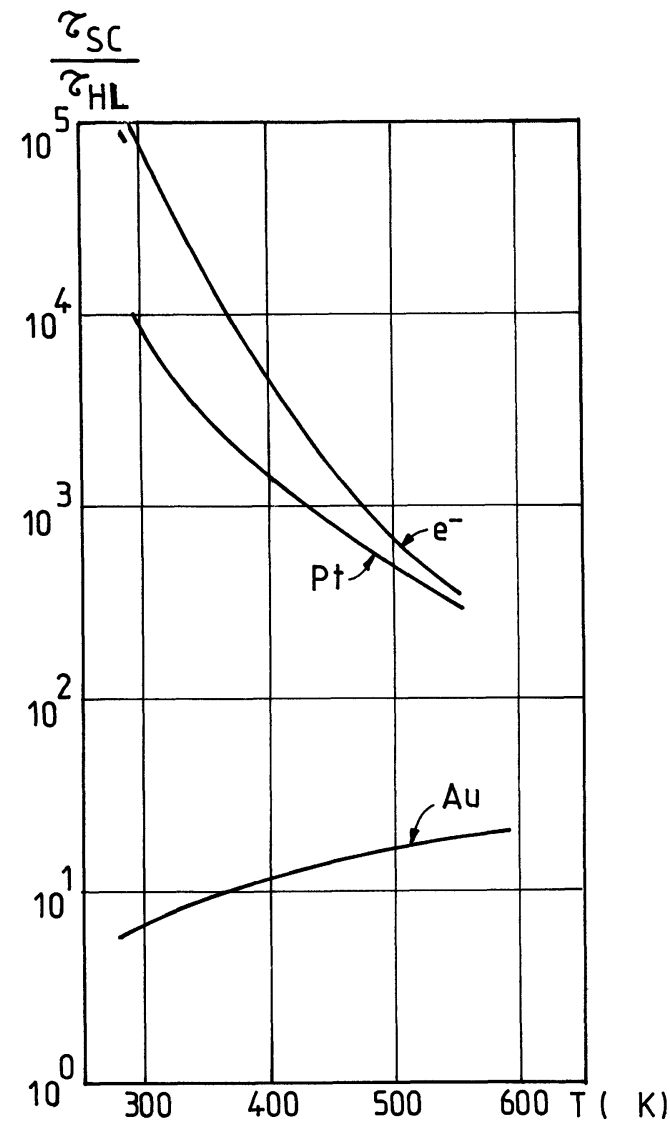

FIG. 7. - Temperature variations of the ratio space charge carrier generation lifetime/high level carrier lifetime, for gold, platinum an electron irradiation induced defects in silicon. 
regions : once the generation rate $U$ has been obtained, $\tau_{\mathrm{SC}} \equiv n_{\mathrm{i}} / U$ is defined. Figure 7 shows the variations of $\tau_{\mathrm{SC}} / \tau_{\mathrm{HL}}$ as a function of temperature, which allows to compare the value obtained for $\tau_{\mathrm{SC}}$ when the same value of $\tau_{\mathrm{HL}}$ has been obtained by the three techniques of carrier lifetime control considered above. In the case of a junction the carrier thermal generation current is the integral of $q U$ over the depleted region of the junction. This current will then be considerably greater in the case of Au-doped silicon devices than in the two other cases.

3. The influence of carrier lifetime on the electrical performance of pin rectifiers. - The main electrical characteristics of power rectifiers which are affected by carrier lifetime are : the forward voltage drop $V_{\mathrm{F}}$, the reverse recovery time $t_{\mathrm{rr}}$ and the reverse steadystate current-voltage characteristic. A detailed analysis of the electrical behaviour of these devices which can be found elsewhere [5], [6] allows to make precise the way in which $\tau_{\mathrm{HL}}, \tau_{\mathrm{LL}}, \tau_{\mathrm{SC}}$ influence those characteristics.

Various authors [7], [8] have dealt with an optimization scheme that allows to compare the different centers which can be used for lifetime control. Such a scheme leads to the following criteria :

$$
\frac{\tau_{\mathrm{HL}}}{\tau_{\mathrm{LL}}} \text { high and } \frac{\tau_{\mathrm{SC}}}{\tau_{\mathrm{HL}}} \text { high } .
$$

The basis for the first criterion is that for a given value of $\tau_{\mathrm{HL}}$, the smallest values of $\tau_{\mathrm{LL}}$ favor fast recovery. However it must be pointed out that :

- this effect is quite small, as shown by numerical calculations [9],

- the value of $\tau_{L L}$ in the I-region of the rectifier is often strongly dependent on the actual value of the impurity concentration (cf. section 2.2),

- if $\tau_{\mathrm{LL}}$ is low, diffusion currents in the heavily doped regions are enhanced, and so is the forward voltage drop [10].
As a consequence, when designing a power rectifier, for a given doping impurity distribution, a proper choice of $\tau_{\mathrm{HL}}$ should be made in order to achieve an acceptable compromise between $V_{\mathrm{F}}$ and $t_{\mathrm{rr}}$, that are to be traded off according to the specific application intended for the device. The value choosen for $\tau_{\mathrm{HL}}$ can be attained with a reduced density of recombination centers in the case of electron irradiation.

The second criterion concerns the other electrical characteristics and is indeed well justified : for a given value of $\tau_{\mathbf{H L}}$, the center that leads to the lower thermal carrier generation current should be chosen. As it has been shown, Pt and electron irradiation lead to better results than Au does.

Finally, some considerations on the practical aspects of the introduction of recombination centers in silicon allow to complete these conclusions : the three techniques involved are used on empirical basis; nevertheless only the use of electron irradiation permits to control accurately the carrier lifetime values by a low temperature process, after device fabrication [11].

4. Conclusion. - The study of the carrier lifetime behaviour for $\mathrm{Au}$ and $\mathrm{Pt}$ doped silicon has shown that an analysis base on a single dominant recombination level cannot be, in general, correct for describing the variations of carrier lifetime with injection. Moreover, the shallow impurity concentration in the starting material has also to be taken into account for it can strongly influence the lifetime value.

The brief considerations made on the influence of carrier lifetime on the electrical performance of PIN rectifiers show that the necessary trade off between forward voltage drop and reverse recovery time has to be attained by a proper choice of the high level lifetime value. Taking into account the influence of the deep centers considered on the other electrical characteristics, and the technological aspects of the use of these centers, the electron irradiation technique appears to suit best the needs of accurate control of carrier lifetime in silicon rectifiers.

\section{References}

[1] Shockley, W., Read, J. R., Phys. Rev. 87 (1952) 835.

[2] Fairfield, J. M., Gokhale, B. V., Solid-State Electron. 8 (1965) 685.

[3] Conti, M., Panchieri, A., Alta Freq. 40 (1971) 544.

[4] Wertheim, C. K., Phys. Rev. 110 (1958) 6.

[5] Cornu, J., Sittig, R., Zimmerman, W., Solid-State Electron. 17 (1974) 1099.

[6] MuÑoz-Yagüe, A., Thèse, Université Paul-Sabatier, Toulouse (1977).
[7] Baliga, B. J., Sun, E., IEDM Technical Digest, paper 20.4 (1976).

[8] Baliga, B. J., Krishna, J., Solid-State Electron. 20 (1977) 225.

[9] Derdouri, M., Thèse de Spécialité, Université Paul-Sabatier, Toulouse (1978).

[10] Muñoz-YagüE, A., LeturcQ, Ph., IEEE Trans. Electron. Devices 28 (1978) 42.

[11] Rai-Choudhury, P., Bartko, J., Johnson, J. E., IEEE Trans. Electron. Devices 23 (1976) 814. 